\title{
Uncoupling of the Infancy Life History Stage
}

\section{Ze'ev Hochberg}

The Ruth and Bruce Rappaport Faculty of Medicine, Technion-Israel Institute of Technology, Haifa, Israel

\section{Keywords}

Human evolution · Life history · Infancy · Infancy-childhood transition

\begin{abstract}
Background: The life history of Homo sapiens is unique in having a comparatively short stage of infancy which lasts for 2-3 years. Infancy is characterized by suckling of breast milk, the development of sensorimotor cognition, the acquisition of language, mini-puberty, deciduous dentition, and almost complete skull growth. Infancy ends with the infancy-childhood growth transition (ICT) and separation from the mother. In modern-day affluent societies, breastfeeding depends on the mother's decision and may happen at any age, and the characteristic traits of infancy have uncoupled. The data and theory for this contention are presented. Summary: The biological traits of mini-puberty and ICT characteristic of infancy occur before age 1 along with language acquisition. The cognitive (sensorimotor) component occurs by age 2 , and the social component of separation from the mother by any age from 1 to 3 years. Key Messages: Human life history is based on a coherent stage of infancy which assumes coupling between the biological, cognitive, and social matura-
\end{abstract}

karger@karger.com

(c) 2021 S. Karger AG, Basel

www.karger.com/hrp

Karger tion of a baby. This is no longer the case in industrial societies and might never be so again. The upbringing of an infant needs to consider the new biology of this dissociated infancy and a new timetable of the infant's life-history events.

(c) 2021 S. Karger AG, Basel

\section{Introduction}

Life-history theory has been advanced to explain the timing of age-specific growth, physical and cognitive development, fertility, and death of living organisms, as well as social events that are tied to these phenomena. The theory is useful in explaining variations in human maturational patterns and understanding how the human life history evolved its unique course among primates [1-5].

Two essential assumptions of life-history theory are that (1) the organism possesses a set of traits dedicated for survival and another set of traits directed toward reproductive fitness; individuals with higher reproductive fitness propagate more of their genes to future generations; traits that are thus maximized by natural selection and (2) these sets of traits are often subject to trade-offs whereby a fitness trait may be limited to maximize benefit from another trait. 
The life history of Homo sapiens is unique in having a relatively short infancy, which lasts for 3 years in traditional societies and ends with weaning from breastfeeding [6]. Infancy is characterized by feeding from maternal breasts, deciduous dentition, rapid and decelerating growth, maturation of the skull to almost its final size, acquisition of unique infantile developmental and social milestones and "mini-puberty" - an early surge of sex hormones. Whereas breastfeeding continues in naturalfertility societies for 24-36 months [7], it stops far earlier and varies much in industrial societies. While initially, the infancy growth stage spanned from birth to 30 months, the next growth stage of childhood sets in among affluent societies before age 1 [8] and significantly later in preindustrial or developing societies [5].

Here, I present the data and theory that in modern-day affluent societies, the various components of infancy have uncoupled: mini-puberty remains a phenomenon of the first year of life; deciduous dentition occurs at age 8-22 months, yet, the primary incisor teeth erupt at the same 6-12 month interval as that of the infancy-childhood growth transition (ICT); breastfeeding duration varies from none at all to 3 years; skull growth will be almost complete at 24 months when the sensorimotor cognitive stage (as defined by Piaget) is also complete [9]. The ICT, which determines $50 \%$ of the variation in the final height, occurs earlier around age 1, with a range from 6 to 14 months $[10,11]$.

\section{Infancy}

The life-history stage of infancy in mammals is defined by weaning from breastfeeding, which happens in traditional human societies at $24-36$ months of age $[7,12]$. Cognitively, during this sensorimotor stage, a child learns about himself and his environment through motor and reflex actions, and thoughts are derived from sensation and movement [9]. The child learns that he is separate from his environment and that aspects of his environment, such as his parents or a favorite toy, continue to exist even though they may be outside the reach of his senses.

If we consider the long life span that now averages 80 years in humans, this period of breastfeeding is relatively short compared to other primates and gives us a large fitness advantage. Wild chimpanzees breastfeed for 60 months; they generally have a life expectancy at birth in the wild of less than 25 years and a mean reproductive life span of about 15 years [13], with a much constrained fitness of 3 pregnancies in the wild. In natural-fertility hu- man societies, the length of infancy may be assessed by the surrogate interbirth interval (IBI), a period spent by the mother in pregnancy and lactation $[7,14,15]$. Thus, the length of infancy is the IBI [-] 9 months of pregnancy. The first IBI is generally shorter than that for later offspring. It lengthens as the number of surviving children increases until the fourth child; after which it does not vary much. For offspring subsequent to the firstborn, mortality increases if the duration of infancy decreases [14]. Thus, the fitness benefit that occurs in humans from more pregnancies (average 7 in traditional societies, as compared to 3 pregnancies in the chimpanzee) is counterbalanced by the energy costs of delivering and caring for more children in a household, including the high energy cost of growth and functioning of the human brain [16]. In a sample of 100 mammalian species, including 23 primates, it was found that the size of brains and adipose depots were negatively correlated, indicating a trade-off between cephalization and fat storage during infancy [16].

\section{Infancy-Childhood Transition in Growth}

In developed countries, there has been a marked secular trend for increased height and a reduction in the age of onset of puberty and menarche over the past 170 years $[17,18]$. This trend is generally understood to be an expression of improved nutrition and general health of children. The evolutionary theory of life history predicts that improved nutrition and general health will result in a reduction in infant and child mortality, increased height, and younger age of puberty so to increase reproductive fitness. The mechanism for the establishment of taller stature is an earlier ICT $[11,19]$. Thus, the average age for ICT is 9 months in Sweden [11], 10 months in Israel [20], 11 months in Shanghai, China [21], and 13 months in Lahore, Pakistan [22] (Fig. 1).

\section{ICT Determination}

The data collected in the first 2 years of life of each subject were fitted using a mathematical model that incorporated the functions and concepts of the Infancy and Childhood components of Karlberg's infancy-childhoodpuberty growth model [8], as previously described [20, 23-25]. The infancy component is modeled with a negative exponential function: $\mathrm{Y}=\mathrm{a}_{\mathrm{I}}+\mathrm{b}_{\mathrm{I}}\left(1-\exp \left(-\mathrm{c}_{\mathrm{I}} \mathrm{t}\right)\right)$, where the birth length is $a_{I}$, the postnatal contribution of the infancy component is $b_{\mathrm{I}}$, and the growth rate of the infancy component is $\mathrm{c}_{\mathrm{I}}$. The childhood component is rep- 
Fig. 1. ICT age as a function of average height. Data for contemporary countries are based on contemporary research [11], and a regression line was calculated. Historical data are based on the regression line. ICT, infancy-childhood transition.

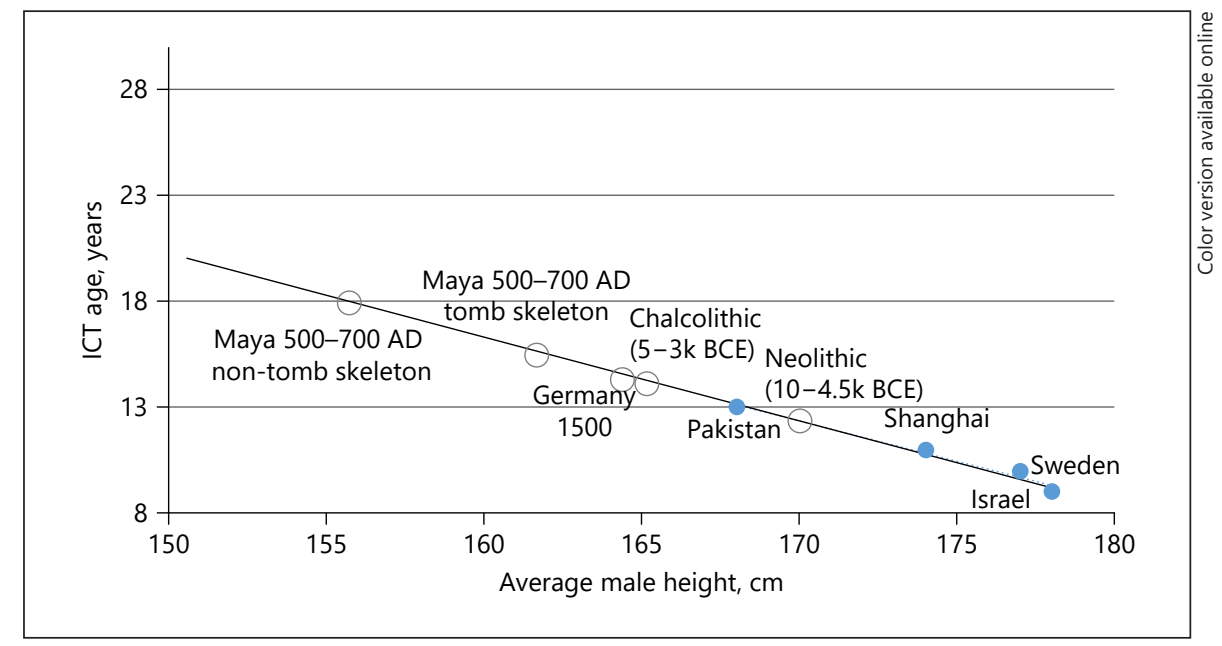

resented by a second-degree polynomial function, where $t$ is age in years: $Y=a_{C}+b_{C} t+c_{C} t^{2}$. All measurements were automatically plotted on the infancy-childhood-puberty growth model charts [10]. The age of the ICT was determined to the nearest month by visual inspection of the plots by 2 observers (interobserver coefficient of variation, CV $<1$ month, $n=100$ ), as previously described $[23,25,26]$.

The timing of ICT evolved to match weaning from breastfeeding, which are both a biological and a cultural event. As a biological process, breastfeeding is grounded in our mammalian descent. From a cultural perspective of modern society, it is contingent upon the mother's personal choice and unrelated in time to her biology.

\section{ICT in Our Ancestors}

The data available on infantile growth in prehuman hominins are limited. In the Pleistocene age (more than 10,000 years before present [BP]), life expectancy at birth was 25 years, like contemporary Agta peasants from the island of Luzon in the Philippines [7, 27], whose IBI is 36 months and duration of breastfeeding is apparently 27 months [7].

While we know little about the growth of ancestral human infants, it is a reasonable assumption that there would have been a link between food supplies and the age at weaning [28]. The agrarian revolution that took place during the transition to the Holocene 12,000 BP was associated with the occurrence of recurring and often severe seasonal food shortages. In a study of contemporary preindustrial societies, we found a strong correlation between average adult body mass and the length of infancy as estimated from the IBI $[7,12]$. The small people of the
Yanomano of the Amazon rainforest, the Kalahari desert's bushman and the Western Pygmy from Cameroon, with females' average body mass of $42-45 \mathrm{~kg}$, wean their babies late at age 31-35 months, while the heavy Wichi people of Argentina and Bolivia, with an average female body mass of $62 \mathrm{~kg}$, breastfeed for a short period of only 12 months (Fig. 1). At 38-22,000 BP, the average height of women was $159 \mathrm{~cm}$ [29], and I estimate from Figure 2 that their average weight has been $53 \mathrm{~kg}$, their IBI 25 months, and their ICT at age 16 months. The shift to agriculture resulted in a decline in food security and height until the industrial revolution in the 18th century. At $1000 \mathrm{CE}$, the average height of males was $170 \mathrm{~cm}$ [30], and based on contemporary CDC2000 data [31], I estimated that the average weight of females was $50 \mathrm{~kg}$ and that ICT occurred at age 21 months (Fig. 2). In 1920, the average height of women was $154.6 \mathrm{~cm}$ [30], as compared to an average of 163 in the CDC2000 data [31], and I estimate that their average weight was $47 \mathrm{~kg}$, as compared to $56 \mathrm{~kg}$ in 2000, and their ICT occurred at age 26 months, as compared to the average in industrial societies of 9-10 months [11].

\section{The Endocrine Basis of Infancy}

Two major endocrine events are prominent during infancy: (1) the ICT when the unique growth pattern, that is, initially independent of the growth hormone (GH)insulin-like growth factor (IGF-1) axis transitions to the $\mathrm{GH}$-dependent growth and (2) the mini-puberty surge of the hypothalamic-pituitary-gonadal (HPG) axis that then subsides. 
Fig. 2. Average female adult mass as a function of the IBIs in 22 preindustrial societies (small circles) [7, 12]. The regression line and 95\% confidence limits are (probably) derived from values of the small circles. The big circles are secondarily added; large open circles indicate the interpolated IBI from the average weights of females at 30,000 years BP, 1000, and 1920 CE [56]. The 2000 CE black circle is based on CDC2000 [31, 57] data and published data on contemporary ICT [11]. ICT, infancychildhood transition; IBI; interbirth interval; BP, before present.

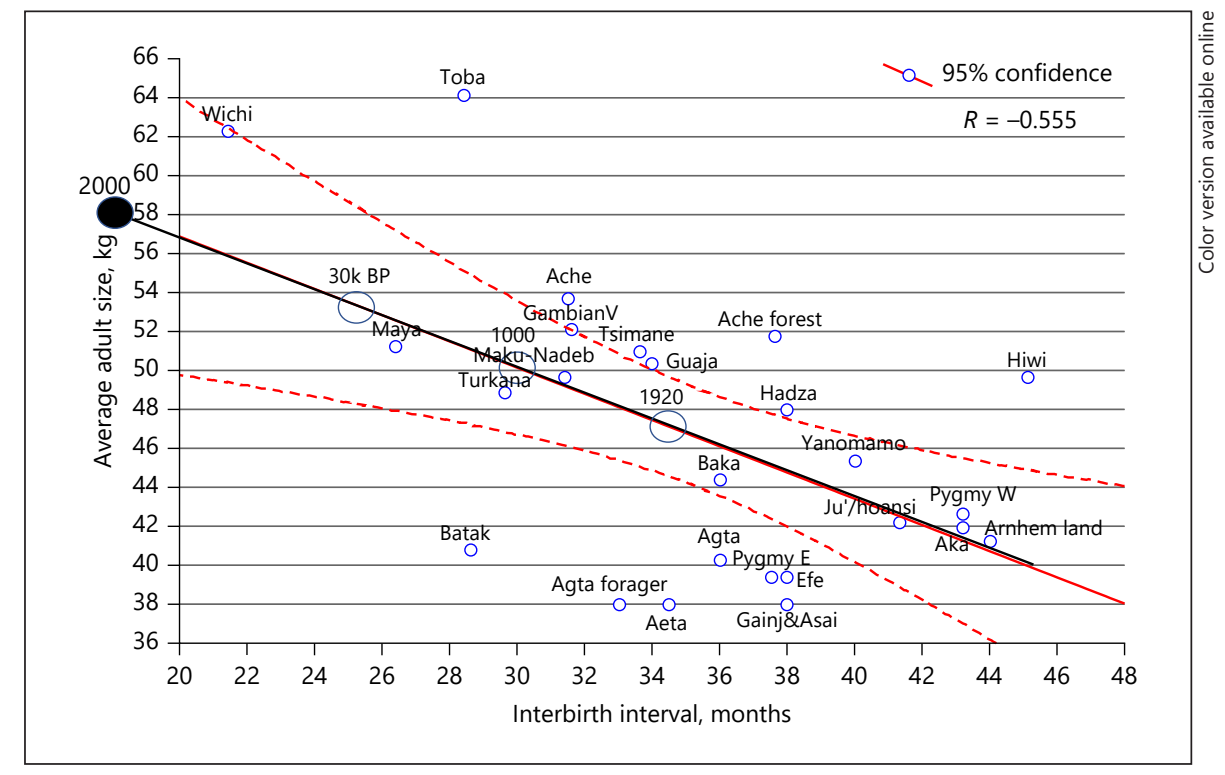

Transition to Dominance of the GH-IGF-1 Axis

Mean serum GH concentrations are higher in newborn infants than in the cord serum at birth, whereas IGFI levels are lower [32] and GH circulating levels are higher in the fetus and newborn than those in later childhood and in adults, but its bioactivity is low and IGF-I levels are low, resembling a state of GH insensitivity [33]. Infantile growth before the ICT is regulated mostly by nutrition, appetite regulating hormones, growth factors in human breast milk, and insulin [34].

The ICT represents the stage at which GH becomes the master regulator of growth, and growth acceleration at the ICT reflects the control of growth by the GH-IGF-I endocrine axis and target cell responsiveness. The onset of the childhood component in healthy subjects, but not in those with GH deficiency, has been observed as an abrupt increase in the growth rate during the second half of the first year of life $[8,35]$. A rise in serum IGF-I and IGF-binding protein-3 levels occurs at the time of the ICT [36].

During infancy, there is a continuous decrease in total sleep time and REM sleep along with a concomitant increase in sleep efficiency and non-REM sleep [37]. It is during non-REM sleep that the thalamic reticular nucleus and cortex pathways activity induce GH release. In nonREM sleep, the inhibitory influence that prevents the spread of arousal activity along the pathways from the brainstem to the cortex is more prominent than in REM sleep. As the infant matures, the frequency of total arousals, cortical arousals, and subcortical activations decrease, affecting GH-inhibitory REM sleep and GH-stimulatory non-REM sleep [38].

The ICT occurs in parallel with a rise in serum levels of GH-dependent IGF-I and IGF-binding protein-3 generation during the second half of the first year of life, and children with a delayed ICT show a delay in the 6-12 months rise of IGF-I levels $[39,40]$. Moreover, an ICT is absent in children with GH deficiency who receive no hormonal therapy [8].

\section{Mini-Puberty}

The second endocrine event of infancy is the so-called mini-puberty, which seems to be crucial to organization of the male's sexual behavior of many mammals. It takes off shortly after parturition, peaks at age 1 month, and wanes more rapidly in boys around age 6 months, than in girls at age 2 [41].

The term mini-puberty denotes the surge in gonadotropin levels [42]; in males, serum LH increases more than in females, and in females, serum FSH increases more than in males. The HPG axis and its negative feedback are operational during this period; in gonadal dysgenesis and Turner's syndrome, the absent negative feedback manifests in high infantile concentrations of gonadotropins $[43,44]$. After peak levels of gonadotropins and sex steroids at 1 month of age, they decline gradually over several months to reach a nadir at 6 months in boys and $2-3$ years in girls $[42,45,46]$. As the infantile hypothalamus matures, it expresses more sex steroid receptors, increasing the hypothalamic sensitivity to the negative 
feedback by minute levels of estrogen, while receiving central nervous system inhibitory signals. Thus, the male's mini-puberty is robust, short, and strongly affects infantile growth, whereas the female's mini-puberty is milder, longer, and hardly affects growth [47].

The quiescence of the HPG at the end of the mini-puberty of the male coincides with the ICT and provides the switch from $\mathrm{GH}$-independent to $\mathrm{GH}$-dependent growth. The female does not undergo a complete HPG quiescence; at the end of infancy, serum FSH and estradiol decline but remain higher than that of the male [48]. Biological activity of the HPG axis is apparent during infan$c y$ : facial comedones and acne-like lesions may be noticed, infantile mammoplasia is common in the female, and testicular volume increases due to an increase in seminiferous tubule size, while Sertoli and germ cells proliferate for about 100 days after birth as a function of high FSH levels [49].

\section{Trade-Offs for the Timing of Weaning}

As part of the adaptive response, the organism may engage in trade-offs between phenotypic traits to secure its short-term survival at the expense of a long-term advantage. These trade-offs mostly concern energy needs to meet the environmental-appropriate metabolic and physiologic demands of a child.

Transitions from one life-history stage to the next are linked to social behaviors and maturation in Homo sapiens as much as it is in other mammals. Synchrony between biological, cognitive, and social traits evolved because transitions from one to the next life-history stages are energetically important, and it would be disadvantageous for social and cognitive maturation to precede the growth and physical maturation, or the other way around. Evolutionary fitness requires that within their limited years of fecundity, mothers deliver as many viable offspring as possible and that they survive at least until they themselves can reproduce [6]. In the case of mammals, evolutionary fitness poses a reproductive dilemma: the intense energetic demands of lactation and the typical physical attachment of mothers to their infant delay the mother's future reproduction [50]. The mechanism for the halt on reproduction is associated with the milk generating hormone prolactin, suppressing the secretion of gonadotropins, and the milk ejector hormone oxytocin - both of which are involved in mother-infant bonding.

In humans, this dilemma is aggravated by even greater energetic demand for rapid infantile brain growth and function on the one hand and a stronger attachment of mother to infant to ensure high-quality infancy on the other. Both are associated with a reduction in the mother's work capacity [51]. Weaning a nursing infant too soon places it at a variety of risks, including increased mortality from environmental hazards and morbidity from infectious and parasitic diseases that potentially restrict growth and development.

The IBI that results from the duration of breastfeeding plus the duration of pregnancy is a measure of the tradeoff between quantity and quality in raising the offspring. Quality of infancy requires the typical parental investment in human offspring to survive to their reproductive age. In traditional societies, the traded-off IBI averages 3 years [7]. If all the traits of infancy persisted for 3 years, growth would be compromised by as much as $21.6 \mathrm{~cm}$ in comparison to the contemporary transition at age 12 months (based on a loss of $0.9 \mathrm{~cm}$ for each month of deferring the ICT [19]). Both body sizes may have major relevance for an individual survival and reproductive fitness [52]. Pygmies are an extreme example of the tradeoff between postnatal growth, survival, and reproductive fitness. Their characteristic small adult size evolved as the result of a life-history trade-off between the fertility benefits in a setting of extremely high childhood and early adulthood mortality [53]. Indeed, the IBI of the Western Pigmies is 43 months and their average menarche age is 15.5 years, as compared to IBI of 21 months of the Wichi of Paraguay, whose average adult weight is $63 \mathrm{~kg}$ and whose menarche occurs at age $13[7,54]$.

\section{Uncoupling of the Infancy Traits}

In a stable environment, the organism adjusts its traits to environmental cues. Thus, the age of maturation of the infant from a sole maternal caretaker (weaning from breastfeeding), to care that is shared by grandmothers, sisters, and other members of the community is linked to other components of the infancy traits bundle. Hence, the age at ICT evolved to match the age of social and cognitive maturation. The ICT age is younger in privileged and later in underprivileged societies. The ICT age can be estimated from the adult height [11], which over the course of history has been quite variable (Fig. 2) [55]. In a study of human-skeleton samples to estimate the height of adults living in Anatolia during the Neolithic $(12,000$ $6,500 \mathrm{BP})$ and Chalcolithic periods $(7,000-5,000 \mathrm{BP})$, average male heights were $170.9 \mathrm{~cm}$ and $165.0 \mathrm{~cm}$, respectively [56]. This decrease has been correlated with the in- 
crease in population density and inadequate nutrition. Pronounced increases were observed for both sexes between the Chalcolithic and Iron (1000-580 BCE) periods, on account of the transition to an agrarian culture and followed by an increase during the Iron period, and height sharply decreased among both males and females in the Hellenistic-Roman period (333 BCE-395 CE) when cereals were the dominant crop, and bread was the staple food. Recovery to the Iron Age, heights occurred in the Anatolian Medieval period (395-1453 CE) for both sexes (169.4 and $158.0 \mathrm{~cm}$, respectively). Height decreased after the "Neolithic agricultural revolution." Later, height slightly increased at the Anatolian Medieval period (395$1453 \mathrm{CE}$ ). This increase might be explained by the fact that Medieval Anatolia benefited from relatively warm climatic conditions. Consequently, quality and quantity of nutrition might have possible effect on medieval heights. In 1884, the mean height of men in Anatolia decreased to $162.2 \mathrm{~cm}$ and by the beginning of the 1930s, it increased to $166.3 \mathrm{~cm}$.

\section{Conclusion}

Rapid environmental changes through improved socioeconomic conditions in modern societies are the basis for the uncoupling of the infancy bundle. In the trade-off of prolonged infancy against taller stature that results from the early ICT, the latter had the upper hand at the cost of uncoupling of the infancy traits. This divergence between the age of biological (mini-puberty and early ICT before age 1), cognitive (end of sensorimotor period at age 18-24 months), and social maturation (separation from the mother and a new pregnancy after age 3 ) has substantial societal implications. Our social structure is based on a coherent life-history stage of infancy, presupposing a match between the developmental, social, and biological maturation of the baby. This is no longer the case and might never be so again. We evolved to have a long coherent infancy in the sole companionship of mothers who now often return to their jobs while still breastfeeding, leaving infants in day care. This is happening while the infant is supposed to make his ICT at age 6-12 months and while his stranger anxiety peak in its intensity. Intercurrent infections, emotional stress by separation from the mother, and care by strangers at this age do not support a smooth growth ICT. Social upbringing of an infant needs to consider the new biology of an uncoupled infancy and a new timetable of the infant's life-history events.

\section{Acknowledgements}

Prof. Lisa Rubin language edited the manuscript.

\section{Statement of Ethics}

This study does not require any ethical approval.

\section{Conflict of Interest Statement}

The author has no conflicts of interest relevant to this study to disclose.

\section{Funding Sources}

This research did not receive any specific grant from funding agencies in the public, commercial, or not-for-profit sectors.

\section{Author Contributions}

Z.H. initiated and wrote the entire manuscript.

\section{References}

1 Harvey PH, Clutton-Brock TH. Life history variation in primates. Evolution. 1985;39(3): 559-81.

2 Charnov E. Life history invariants: some explorations of symmetry in evolutionary ecology, 1993. Oxford, UK: Oxford University Press; 1993.

3 Hill K. Life history theory and evolutionary anthropology. Evol Anthropol. 1993;2:78-88.
4 Bogin B, Silva MI, Rios L. Life history tradeoffs in human growth: adaptation or pathology? Am J Hum Biol. 2007 Sep-Oct;19(5): 631-42.

5 Hochberg Z. Evo-devo of child growth II: human life history and transition between its phases. Eur J Endocrinol. 2009 Feb;160(2): $135-41$.

6 Hochberg Z. Evo devo of child growth: treatize on child growth and human evolution. New York, NY: Wiley; 2012.
7 Gawlik A, Walker RS, Hochberg Z. Impact of infancy duration on adult size in 22 subsistence-based societies. Acta Paediatr. 2011 Jul 4;100:e248-52.

8 Karlberg J, Albertsson-Wikland K. Infancy growth pattern related to growth hormone deficiency. Acta Paediatr Scand. 1988 May; 77(3):385-91.

9 Piaget J. The origins of intelligence in children. New York, NY: International University Press; 1936. 
10 Karlberg J, Engström I, Karlberg P, Fryer JG. Analysis of linear growth using a mathematical model. I. From birth to three years. Acta Paediatr Scand. 1987 May;76(3):478-88.

11 Hochberg Z, Albertsson-Wikland K. Evo-devo of infantile and childhood growth. Pediatr Res. 2008 Jul;64(1):2-7.

12 Walker R, Gurven M, Hill K, Migliano A, Chagnon N, De Souza R, et al. Growth rates and life histories in twenty-two small-scale societies. Am J Hum Biol. 2006 May-Jun; 18(3):295-311.

13 Courtenay J, Santow G. Mortality of wild and captive chimpanzees. Folia Primatol. 1989; 52(3-4):167-77.

14 Blurton Jones N. Bushman birth spacing: direct tests of some simple predictions. Ethol Sociobiol. 1987;8(3):183-203.

15 Sellen DW. Comparison of infant feeding patterns reported for nonindustrial populations with current recommendations. J Nutr. 2001 Oct;131(10):2707-15.

16 Navarrete A, van Schaik CP, Isler K. Energetics and the evolution of human brain size. $\mathrm{Na}$ ture. 2011;480(7375):91-3.

17 Cole TJ. Secular trends in growth. Proc Nutr Soc. 2000;59:317-24.

18 Brune M, Hochberg Z. Secular trends in new childhood epidemics: insights from evolutionary medicine. BMC Med. 2013;11:226.

19 Liu Y, Albertsson-Wikland K, Karlberg J. Long-term consequences of early linear growth retardation (stunting) in Swedish children. Pediatr Res. 2000 Apr;47(4 Pt 1): $475-80$.

20 German A, Livshits G, Peter I, Malkin I, Dubnov J, Akons $\mathrm{H}$, et al. Environmental rather than genetic factors determine the variation in the age of the infancy to childhood transition: a twins study. J Pediatr. 2015;166(3): $731-5$.

21 Xu X, Wang W, Guo Z, Karlberg J. Longitudinal growth during infancy and childhood in children from Shanghai: predictors and consequences of the age at onset of the childhood phase of growth. Pediatr Res. 2002 Mar;51(3): $377-85$.

22 Karlberg J, Jalil F, Lam B, Low L, Yeung CY. Linear growth retardation in relation to the three phases of growth. Eur J Clin Nutr. 1994 Feb;48(Suppl 1):S25-4; discussion S43-4.

23 Albertsson-Wikland K, Kristrom B, Hochberg Z. Delayed infancy-childhood spurt (DICS) in GHD. Horm Res. 2007;68(Suppl 1): 168.

24 Kristrom B, Hochberg Z, Albertsson-Wikland K. Delayed infancy-childhood spurt (DICS) in idiopathic short stature (ISS) Horm Res. 2007;68(Suppl 1):168.

25 Albertsson-Wikland K, Kriström B, Jonsson $\mathrm{B}$, Hochberg Z. Long-term response to $\mathrm{GH}$ therapy in short children with a delayed infancy-childhood transition (DICT). Pediatr Res. 2011 Jun;69(6):504-10.
26 Karlberg J, Albertsson-Wikland K, Nilsson KO, Ritzén EM, Westphal O. Growth in infancy and childhood in girls with Turner's syndrome. Acta Paediatr Scand. 1991 Dec; 80(12):1158-65.

27 Walker RS, Gurven M, Burger O, Hamilton MJ. The trade-off between number and size of offspring in humans and other primates. Proc Biol Sci. 2008 Apr 7;275(1636):827-33.

28 Shaoul R, Tiosano D, Hochberg Z. Evo-devo of child growth: the role of weaning in the transition from infancy to childhood. Crit Rey Food Sci Nutr. 2015 May 27;56:887-95.

29 Gallagher A. Stature, body mass, and brain size: a two-million-year odyssey. Econ Hum Biol. 2013;11(4):551-62.

30 Roser M, Appel C, Ritchie H. Human height. Our world in data. 2013.

31 Kuczmarski RJ. 2000 CDC growth charts for the United States: methods and development. Department of Health and Human Services, Centers for Disease Control; 2002.

32 De Zegher F, Devlieger H, Veldhuis JD. Properties of growth hormone and prolactin hypersecretion by the human infant on the day of birth. J Clin Endocrinol Metab. 1993;76(5): 1177-81.

33 de Zegher F, Kimpen J, Raus J, Vanderschueren-Lodeweyckx M. Hypersomatotropism in the dysmature infant at term and preterm birth. Biol Neonate. 1990;58(4):188-91.

34 Fields DA, Demerath EW. Relationship of insulin, glucose, leptin, IL-6 and TNF- $\alpha$ in human breast milk with infant growth and body composition. Pediatr Obes. 2012;7(4):30412.

35 Wit JM, van Unen H. Growth of infants with neonatal growth hormone deficiency. Arch Dis Child. 1992 Jul;67(7):920-4.

36 Low LC, Tam SY, Kwan EY, Tsang AM, Karlberg J. Onset of significant GH dependence of serum IGF-I and IGF-binding protein 3 concentrations in early life. Pediatr Res. $2001 \mathrm{Dec}$ Jan;50(6):737-42.

37 Louis J, Cannard C, Bastuji H, Challamel MJ Sleep ontogenesis revisited: a longitudinal 24hour home polygraphic study on 15 normal infants during the first two years of life. Sleep. 1997 May;20(5):323-33.

38 Montemitro E, Franco P, Scaillet S, Kato I, Groswasser J, Villa MP, et al. Maturation of spontaneous arousals in healthy infants. Sleep. 2008 Jan 1;31(1):47-54.

39 Wang HS, Chard T. The role of insulin-like growth factor-I and insulin-like growth factor-binding protein-1 in the control of human fetal growth. J Endocrinol. 1992 Jan;132(1): 11-9.

40 Leger J, Oury JF, Noel M, Baron S, Benali K, Blot $\mathrm{P}$, et al. Growth factors and intrauterine growth retardation. I. Serum growth hormone, insulin-like growth factor (IGF)-I, IGF-II, and IGF binding protein 3 levels in normally grown and growth-retarded human fetuses during the second half of gestation. Pediatr Res. 1996 Jul;40(1):94-100.
41 Kuiri-Hänninen T, Sankilampi U, Dunkel L. Activation of the hypothalamic-pituitary-gonadal axis in infancy: minipuberty. Horm Res Paediatr. 2014;82(2):73-80.

42 Burger HG, Yamada Y, Bangah ML, McCloud PI, Warne GL. Serum gonadotropin, sex steroid, and immunoreactive inhibin levels in the first two years of life. J Clin Endocrinol Metab. 1991 Mar;72(3):682-6.

43 Conte FA, Grumbach MM, Kaplan SL. A diphasic pattern of gonadotropin secretion in patients with the syndrome of gonadal dysgenesis. J Clin Endocrinol Metab. 1975;40(4):670-4.

44 Van Vliet G. Hormonal changes during development in Turner's syndrome. Acta Paediatr Scand Suppl. 1988;343:31-7.

45 Winter JS, Faiman C. Pituitary-gonadal relations in female children and adolescents. Pediatr Res. 1973 Dec;7(12):948-53.

46 Grumbach MM. A window of opportunity: the diagnosis of gonadotropin deficiency in the male infant. J Clin Endocrinol Metab. 2005 May;90(5):3122-7.

47 German A, Hochberg Z. Sexual dimorphism of size ontogeny and life history. Front Pediatr. 2020;8:387.

48 Klein KO, Baron J, Colli MJ, McDonnell DP, Cutler GB Jr. Estrogen levels in childhood determined by an ultrasensitive recombinant cell bioassay. J Clin Invest. 1994 Dec;94(6): 2475-80.

49 Muller J, Skakkebaek NE. Quantification of germ cells and seminiferous tubules by stereological examination of testicles from 50 boys who suffered from sudden death. Int $J$ Androl. 1983 Apr;6(2):143-56.

50 Kennedy GE. From the ape's dilemma to the weanling's dilemma: early weaning and its evolutionary context. J Hum Evol. 2005;48(2): $123-45$.

51 Lee PC. The meanings of weaning: growth, lactation, and life history. Evol. Anthropol. 1996;5(3):87-98.

52 Jolley CD. Failure to thrive. Curr Probl Pediatr Adolesc Health Care. 2003;33(6):183-206.

53 Migliano AB, Vinicius L, Lahr MM. Life history trade-offs explain the evolution of human pygmies. Proc Natl Acad Sci USA. 2007 Dec 18;104(51):20216-9.

54 Hochberg Z, Gawlik A, Walker RS. Evolutionary fitness as a function of pubertal age in 22 subsistence-based traditional societies. Int J Pediatr Endocrinol. 2011;2011(1):2.

55 Schwidetzky I, JÄGER HJ. The data base for prehistorical and historical anthropology in Mainz. Homo. 1991;42(2):163-70.

56 Özer BK, Sağır M, Özer İ. Secular changes in the height of the inhabitants of Anatolia (Turkey) from the 10th millennium $B C$ to the 20th century AD. Econ Human Biol. 2011;9(2):211-9.

57 Kuczmarski RJ, Ogden CL, Guo SS, Grummer-Strawn LM, Flegal KM, Mei Z, et al. 2000 CDC Growth Charts for the United States: methods and development. Vital Health Stat 11. 2002;(246):1-190. 